\title{
EXPANSIÓN URBANA EN CIUDADES INTERMEDIAS DE CRECIMIENTO DEMOGRÁFICO BAJO. EL CASO DE BAHÍA BLANCA, ARGENTINA.
}

\author{
Guillermina Urriza \\ Departamento de Geografía y Turismo, Universidad Nacional del Sur \\ gurriza@uns.edu.ar
}

\section{RESUMEN}

En las últimas décadas se observan procesos de extensión de la superficie urbana de modo disperso y en baja densidad en la periferia de ciudades intermedias, que requieren ser explicados desde la particularidad de sus causas y formas de ocupación, así como también por los actores intervinientes y sus relaciones en el proceso de producción y transformación morfológica y funcional de este espacio. En este contexto, resulta llamativo el proceso de expansión de la superficie urbana construida en algunas ciudades donde el crecimiento demográfico es bajo. Se ha seleccionado el caso de Bahía Blanca (291 mil habitantes), importante centro de servicios y nodo regional del sudoeste de la Provincia de Buenos Aires. A pesar de registrar un incremento poblacional muy moderado, evidencia una notable expansión de la superficie urbanizada en la periferia como también una verticalización del área central. El presente trabajo comprende los primeros avances en la formulación del proyecto de tesis de doctorado en Estudios Urbanos de la Universidad Nacional del General Sarmiento.

Palabras clave: expansión urbana - dispersión - periferia - ciudad intermedia

\begin{abstract}
In recent decades there have been processes of extension of the urban surface in a dispersed and low density manner in the periphery of intermediate cities, which need to be explained from the particularity of their causes and forms of occupation, as well as by the intervening actors and their relationships in the process of production and morphological and functional transformation of this space. In this context, the process of expansion in some cities where population growth is low is striking. It has been selected the case of Bahía Blanca (291 thousand inhabitants), an important service center and a regional node of the southwest of the Province of Buenos Aires. Despite registering a very moderate population increase, this city evidences a notable expansion of the urbanized area in the periphery as well as a verticalization of the central area. The present work includes the first advances in the formulation of the PhD thesis project in Urban Studies at the National University of General Sarmiento.
\end{abstract}

Key words: urban expansion - dispersion - periphery - intermediate city 


\section{INTRODUCCIÓN}

Se reconocen básicamente dos formas de crecimiento espacial de las ciudades: éstas pueden crecer por verticalización y también pueden extenderse en superficie incorporando al uso urbano tierras de la periferia. Atento a cuál de estas formas es dominante y cómo se materializa en el espacio urbano, se plantea la dicotomía entre ciudades compactas y ciudades dispersas.

Existe una variada bibliografía que aborda diferentes aspectos vinculados a estos modelos (Indovina, 2007; Monclus, 1998; Entrena Durán, 2005; Moliní y Salgado, 2012; Magrinyà y Herce, 2007; Cárdenas Ropero, 2012; Chavoya Gama et. al, 2009, entre otros), entendiendo que la urbanización compacta se caracteriza por una trama urbana contigua y densidades medias o altas; mientras que la ciudad dispersa presenta un proceso de ocupación del espacio urbano discontinuo, predominantemente en baja densidad y en extensión, con tramas urbanas formadas generalmente por viviendas unifamiliares. Claro está que se trata de modelos teóricos de ciudad, y que en una misma aglomeración pueden convivir diversas tramas urbanas.

A medida que el proceso de urbanización avanza en el mundo, la discusión sobre la densidad y extensión de las ciudades, la forma y sustentabilidad urbanas cobra cada vez más relevancia. No se trata sólo de una preocupación ambiental, sino también se cuestiona la calidad de vida, las condiciones de equidad social y las implicancias económicas que estas formas de urbanización suponen. En definitiva se debate si, dado un crecimiento poblacional determinado, es mejor que éste ocupe el suelo de manera razonablemente compacta o, por el contrario, de forma extensa y en baja densidad.

En este contexto se debe considerar que el crecimiento por extensión no afecta exclusivamente a las grandes ciudades, sino que se observan procesos de expansión en las periferias de ciudades intermedias, que no pueden atribuirse a la demanda de suelo necesario para absorber el incremento poblacional. Tal es el caso de ciudades que experimentan un crecimiento demográfico lento, no obstante la mancha urbana crece a un ritmo notablemente superior, situación que resulta alarmante.

El presente trabajo comprende los primeros avances en la formulación del proyecto de tesis de doctorado en Estudios Urbanos de la Universidad Nacional del General Sarmiento. El tema central objeto de estudio es el fenómeno de expansión urbana en ciudades intermedias de crecimiento demográfico bajo. En primer lugar se plantean los aspectos metodológicos de la investigación formulados en el marco del taller de tesis y una breve reseña histórico-geográfica del área de estudio. Luego se aborda el crecimiento demográfico de Bahía Blanca, en relación a otras ciudades intermedias de la Provincia de Buenos Aires, seguido de la identificación preliminar de diferentes tejidos residenciales en el crecimiento urbano bahiense. Se concluye con un apartado referido a la expansión desde la perspectiva de los planes urbanos.

\section{ASPECTOS METODOLÓGICOS DE LA INVESTIGACIÓN}

La comunidad internacional de investigadores ha estudiado ampliamente el fenómeno de urbanización expansiva, dispersa y en baja densidad de las grandes ciudades. En un contexto en el que se ha intensificado el crecimiento por extensión de las áreas metropolitanas, las periferias de estas aglomeraciones experimentan un significativo dinamismo socioeconómico e importantes transformaciones, diferenciándose cada vez más de las formas de la ciudad compacta. Estos procesos se han visto reflejados en la literatura académica que ha promovido el análisis y debate sobre los factores explicativos de este fenómeno, la calidad de vida, la sustentabilidad y las consecuencias que implica esta forma de expansión de la urbanización en las grandes ciudades.

Sin embargo, no se trata de un fenómeno vinculado exclusivamente a los centros urbanos mayores de países desarrollados o ciudades de países en desarrollo que registran un alto crecimiento demográfico y económico. En las últimas décadas se observan procesos de extensión de la superficie urbana de modo disperso y en baja densidad en la periferia de ciudades intermedias, que requieren ser explicados desde la particularidad de sus causas y formas de ocupación, así como también por los actores intervinientes y sus relaciones en el proceso de producción y transformación morfológica y funcional de este espacio. Las ciudades intermedias de la Provincia de Buenos Aires no están ajenas a estos procesos, por lo tanto es importante analizar este fenómeno a la luz de las estructuras urbanas y dinámicas propias de estos centros, En este contexto, resulta llamativo el proceso de expansión de la superficie urbana construida en ciudades que no registran una dinámica demográfica intensa.

Al realizar una revisión bibliográfica se puede observar que se emplean distintos términos para explicar el 
fenómeno de crecimiento de la periferia de las ciudades. Se hace referencia, muchas veces indistintamente, a términos como disperso y difuso, periurbanización, suburbanización, rururbanización y contraurbanización, entre otros, que plantean la necesidad de realizar oportunamente una diferenciación conceptual, acorde a la escala de ciudad, los procesos que procuran explicar y el contexto geográfico donde se desarrollan.

Se plantean preliminarmente las siguientes preguntas de investigación:

- ¿Por qué las ciudades intermedias experimentan un notorio proceso de expansión urbana? ¿Cuáles son los factores locales y exógenos que impulsan este proceso?

- ¿Cómo influye el Estado en el proceso de expansión urbana de ciudades intermedias y cómo se relacionan los diferentes actores (Estado, agentes inmobiliarios y grupos sociales)?

El objetivo general de la investigación es contribuir al conocimiento del fenómeno de expansión urbana en la periferia de ciudades intermedias. Y persigue los siguientes objetivos específicos:

I. Reconocer los procesos urbanos que caracterizan el fenómeno de expansión urbana en ciudades intermedias para explicar por qué y cómo se produce, y cómo se diferencia o no del que se desarrolla en las grandes ciudades.

II. Analizar el rol del Estado, el mercado inmobiliario y los diferentes grupos sociales en el proceso de expansión urbana de ciudades intermedias para explicar cómo se articulan las lógicas de acción de los actores que configuran morfológica y socioespacialmente la periferia.

III. Profundizar en la diversa terminología utilizada para explicar los procesos de urbanización en la periferia urbana (periurbanización, suburbanización, rururbanización, entre otros) a fin de realizar una contribución conceptual al abordaje de estos fenómenos en ciudades intermedias, acorde al contexto geográfico y sociocultural donde tienen lugar.

Atento a las preguntas de investigación, se han formulado en principio dos hipótesis:

- El fenómeno de expansión urbana en la periferia de las ciudades intermedias reproduce los patrones de urbanización característicos de grandes ciudades, independientemente de su tamaño demográfico y crecimiento poblacional.

- La lógica de acción del Estado en materia de política urbana favorece los intereses del mercado inmobiliario y los grupos sociales de mayor poder económico.

Se trata de una investigación empírica exploratoria con un enfoque metodológico fundamentalmente cualitativo. Se pretende analizar en profundidad el problema de investigación mediante la técnica de estudio de caso. Se ha seleccionado la ciudad intermedia de Bahía Blanca (291.327 habitantes) que constituye un importante nodo regional del sudoeste bonaerense. A pesar de su relevante rol de intermediación en una amplia área de influencia, en el período 1991-2010 el crecimiento poblacional fue bajo (12\%), registrando la menor variación demográfica en el conjunto de ciudades intermedias de la Provincia de Buenos Aires. No obstante, en este período la superficie urbana construida creció un $89 \%$ y la densidad promedio de población descendió de $76 \mathrm{hab} / \mathrm{ha}$ a $45 \mathrm{hab} / \mathrm{ha}$. Si bien la investigación se focaliza en la escala local, atento a la complejidad del objeto de estudio, se procurará explorar el fenómeno en otras escalas a fin de indagar sobre causalidades exógenas que actúan en el ámbito local.

Existe variada bibliografía que aborda diferentes aspectos vinculados a los procesos de urbanización expansiva en las grandes ciudades de países desarrollados, así como también el crecimiento de las áreas metropolitanas latinoamericanas. En cuanto al estado del arte, en el ámbito nacional y en relación a las ciudades intermedias, un antecedente reciente es la tesis doctoral de Frediani (2010) que desarrolla el estudio de las lógicas y tendencias del proceso de expansión residencial en el espacio periurbano de la ciudad de La Plata (800 mil habitantes) en el período 1990-2010. Por su parte, Ríos y Rocca (2014) -en el marco de una investigación denominada "Procesos de expansión urbana, políticas territoriales y transformaciones emergentes"- plantean el problema del fenómeno de expansión urbana de forma dispersa en ciudades de rango intermedio con dinámicas demográficas y económicas intensas, analizando el caso de Tandil (116 mil habitantes). ${ }^{1}$ También en el ámbito bonaerense, es dable señalar los aportes de las

${ }^{1}$ En el período intercensal 1991-2010, la ciudad de Tandil registró un crecimiento del 27,5\%. 
publicaciones de Zulaica, Ferraro y otros autores sobre la expansión urbana de Mar del Plata y las transformaciones del periurbano de esta ciudad intermedia de 593 mil habitantes.

Asimismo en el ámbito internacional cabe mencionar, entre otros, la publicación de Bellet et al (2015), que reúne textos de investigadores de Argentina, Brasil, Chile, Ecuador, México y España, relativos a dos ejes temáticos: dinámicas de producción y consumo, y urbanización y dinámicas inmobiliarias en ciudades intermedias. En tanto Cebrián Abellán y Panadero Moya (2013), en su libro Ciudades Medias: Formas de expansión urbana, analizan el fenómeno de "difusión urbana" en ciudades de entornos culturales diferenciados como España, Polonia y Estados Unidos.

\section{PRESENTACIÓN DEL ÁREA DE ESTUDIO}

Bahía Blanca se encuentra localizada sobre la costa atlántica, al sudoeste de la provincia de Buenos Aires. Según su tamaño demográfico (291 mil habitantes) puede definirse como una ciudad media. ${ }^{2}$ No obstante, al tener en cuenta sus funciones adquiere la categoría de intermedia puesto que constituye un destacado nodo de comunicaciones y transporte a escala nacional, así como también un importante centro de servicios de una de las principales zonas agroexportadoras del país. Además se distingue por la producción industrial petroquímica, su puerto de aguas profundas, las actividades gubernamentales, la oferta educativa de sus universidades y un diversificado sector comercial. Esta variedad de funciones explica su rol de intermediación en una amplia área de influencia y su jerarquía como centro urbano regional.

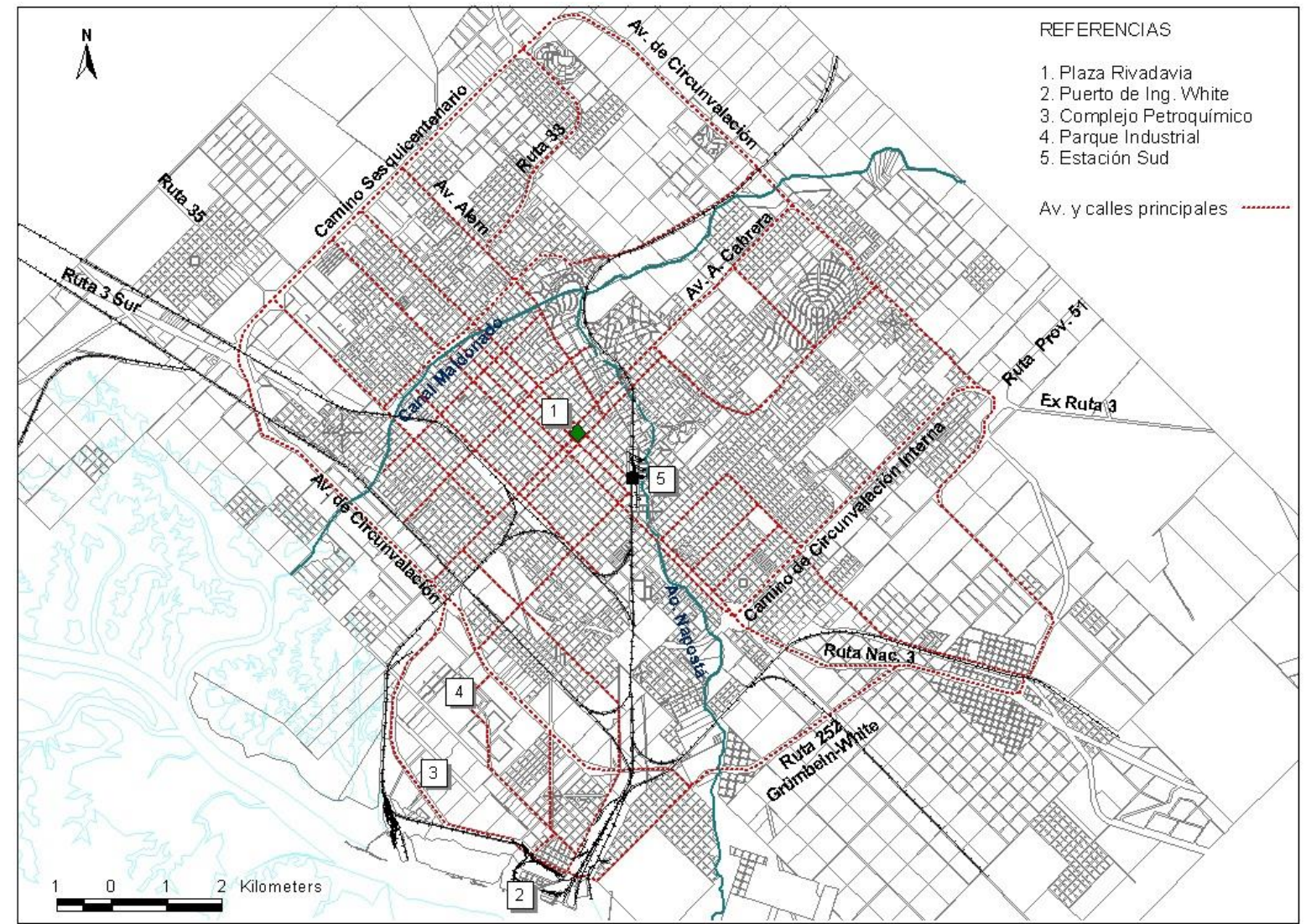

Área de estudio: ciudad de Bahía Blanca

Elaboración propia

Fundada en 1828 como fuerte de avanzada en la "conquista del desierto", la ciudad creció siguiendo el amanzanamiento típico ortogonal de la colonización española, prolongando una grilla predominantemente regular, orientada a medio rumbo, en el valle inferior del Arroyo Napostá Grande. Las denominadas terrazas del sector alto -al norte y noreste de la ciudad- y la presencia de los arroyos Napostá Grande y Maldonado se destacan en un relieve llano con suave pendiente hacia el mar. La planicie costera constituye un ambiente bajo, de terrenos fangosos y anegadizos en algunos sectores.

${ }^{2}$ El concepto de ciudad media refiere al tamaño demográfico, en tanto la noción de intermedia incorpora la dimensión cualitativa y se basa en las funciones y el rol de mediación de estas ciudades en los diversos flujos que se establecen entre los espacios rurales y urbanos del área de influencia y territorios más alejados, regionales, nacionales y también globales (Bellet y Llop, 2004). 
Teniendo en cuenta las condiciones del medio natural para la expansión urbana, cabe señalar que la zona norte y noroeste de la ciudad es la más apta, mientras los sectores ubicados al este presentan un nivel de aptitud media, requiriendo un control del drenaje superficial. Por su parte, el área sur y sudoeste resulta la menos apropiada para la urbanización puesto que los terrenos son bajos, sin pendiente natural y la napa freática se encuentra muy cercana a la superficie; a ello se suma la cercanía del polo petroquímico y el parque industrial (Zinger y Del Pozo, 1990).

\subsection{Breve reseña del proceso de crecimiento urbano de Bahía Blanca}

Si bien las condiciones naturales del medio fueron relevantes al momento de elegir el sitio para su fundación, con el tiempo se convirtieron -junto con el trazado del ferrocarril- en un obstáculo para la expansión urbana, dificultando la conectividad entre diferentes sectores. No obstante, la ciudad sostuvo un crecimiento fundamentalmente radioconcéntrico que traspasaría las barreras impuestas por los cursos de agua y la estructura ferroviaria.

Desde los inicios, las principales funciones políticas y administrativas se localizaron en torno a la Plaza Rivadavia, mientras que hacia fines del siglo XIX, la actividad comercial se organizó en las calles próximas a la Estación Sud del Ferrocarril. Las industrias y depósitos se ubicaron principalmente sobre las márgenes del Arroyo Napostá y en proximidad de las vías férreas; en tanto, la franja costera permanecía escasamente poblada debido a las condiciones de habitabilidad menos favorables. Entre los años 1880 y 1930 la ciudad experimentó una etapa de modernización y expansión, producto del modelo agroexportador vigente en el país (MBB, 2000).

En la primera mitad del siglo XX el crecimiento se orientó espontáneamente hacia el este y noreste, buscando sectores más altos, resguardados de las frecuentes inundaciones provocadas por el Arroyo Napostá. Debido a los costos de urbanización generados por una mayor pendiente, el proceso de ocupación luego se desplazó hacia el oeste donde el declive es más suave. En tanto, a mediados de siglo XX, comenzó a manifestarse la verticalización del área central con el surgimiento de la edificación en altura en proximidad a la Plaza Rivadavia. La actividad comercial entonces se fue desplazando fundamentalmente hacia el entorno de esta plaza donde se consolidaría el centro principal de la ciudad.

La construcción de conjuntos habitacionales en terrenos de menor valor y más alejados del área central, y el crecimiento de los asentamientos irregulares en ciertos sectores de la ciudad, comenzaron a manifestarse como elementos importantes en la estructura urbana, fundamentalmente a partir de los años '70, acentuando su presencia e impronta en las siguientes décadas. Mientras tanto la presencia del puerto y la instalación del complejo petroquímico en 1981 promovieron el crecimiento hacia el sur, a pesar de las condiciones del medio natural menos apropiadas. ${ }^{3}$

A partir de la concreción del Camino de Circunvalación Externa y la Avenida de Penetración Alberto Cabrera a mediados de 1990, Bahía Blanca evidenció una notoria expansión hacia la zona alta al mejorar la accesibilidad y la comunicación entre la periferia y el área central. A fines de esa década, se registraban importantes transformaciones en el uso y ocupación de la franja periurbana del noreste y norte de la ciudad, tales como la radicación de dos grandes superficies comerciales (Wal Mart-Paseo del Sol y Bahía Plaza Shopping), la progresiva retracción de usos productivos (fundamentalmente horticultura), el surgimiento de nuevos proyectos inmobiliarios para el estrato de ingresos medio y medio-alto, y un fuerte crecimiento residencial. Estos cambios se vieron reflejados en el aumento de la demanda y valorización de la tierra en el sector, conformándose la Av. Cabrera como el eje preferencial de crecimiento y desarrollo de una nueva centralidad, que no llegaría a reemplazar el centro histórico tradicional.

Dentro de este contexto, en los últimos veinte años adquirió relevancia la promoción de parcelas tipo barrio parque y en urbanizaciones cerradas, en la zona alta de la ciudad donde, según el Código de Planeamiento Urbano, el uso predominante es el residencial parque. ${ }^{4}$ Los loteos incorporados al mercado en la década de

\footnotetext{
3 En el año 1968 Bahía Blanca fue declarada Polo de Crecimiento Provincial de la Región del Comahue. La construcción del Dique Paso de las Piedras sobre el Río Sauce Grande para abastecimiento de agua a la ciudad (1978), la radicación de la Planta de Petroquímica Bahía Blanca (1981) próxima al Puerto de Ing. White, y la habilitación de la Central Termoeléctrica Luis Piedra Buena (1989) sustentaron el desarrollo industrial del sector costero. Este fue acompañado de la construcción de barrios cercanos a esta fuente de trabajo, así como también del mejoramiento de la infraestructura vial y urbana (MBB, 2000).

${ }^{4}$ La zona residencial parque es un área de vivienda unifamiliar de baja densidad, con traza de barrio parque y tejido abierto, con retiros de frente y laterales. El Rp 1 exige una subdivisión mínima de $600 \mathrm{~m}^{2}$ (20 m de frente), y el Rp 2 de $400 \mathrm{~m}^{2}$ (17 m de frente) permite vivienda bifamiliar.
} 
1990 evidencian una paulatina consolidación y la oferta de suelo se ha ampliado a partir de nuevos emprendimientos. Estos loteos son generalmente comercializados por empresas inmobiliarias que orientan la oferta fundamentalmente a familias con solvencia económica, promocionando en muchos casos parcelas de un tamaño relativo mayor en un entorno verde, de calidad ambiental y paisajística.

Además se amplió la superficie ocupada por los conjuntos habitacionales, construidos en muchos casos por entidades intermedias. En su gran mayoría se emplazaron en los sectores noroeste y sur, y en menor medida en el este, donde el Código de Planeamiento Urbano lo permite. A partir del año 2007, comenzaron a edificarse los conjuntos del Programa Federal de Construcción de Vivienda, tanto en terrenos públicos como privados. En el primer caso se ubicaron preferentemente en el sector sudoeste de la ciudad; en tanto los conjuntos gestionados por entidades intermedias se localizan mayoritariamente en el sector este de la ciudad.

Por otra parte, la ocupación informal de tierras (públicas y privadas) efectuada por familias de escasos recursos también ha contribuido a la expansión de la ciudad, fundamentalmente en los sectores oeste, sudoeste y sur de la periferia. Estas áreas presentan condiciones precarias de habitabilidad y déficit en la dotación de infraestructura y equipamiento.

Se puede observar como la mancha urbana ha traspasado la Circunvalación Externa, mediante el crecimiento residencial unifamiliar, como también por la construcción de conjuntos habitacionales y la incorporación de loteos tipo barrio parque y una urbanización cerrada. Esta vialidad estructurante no sólo no ha contenido el crecimiento sino que ha promovido el avance de la urbanización al favorecer la accesibilidad y comunicación de la periferia con el área central y otros sectores de la ciudad.

Simultáneamente Bahía Blanca ha experimentado un importante proceso de verticalización a partir de la construcción de un gran número de edificios en el área central. En todo caso, verificaría un doble proceso de expansión urbana: uno vertical dado por el crecimiento en altura en el centro, propio de la ciudad compacta, y otro horizontal, mediante la extensión en baja densidad en la periferia.

\section{CRECIMIENTO DEMOGRÁFICO DE LAS CIUDADES INTERMEDIAS BONAERENSES, 1991-2010}

Desde la década de 1990 las aglomeraciones de tamaño intermedio (ATIs) argentinas, de 50.000 hasta 999.999 habitantes, han evidenciado un importante dinamismo. Éstas han crecido y se han diversificado, razón por la cual Di Nucci y Linares (2016) han propuesto diferenciarlas en tres subcategorías: AT/s mayores (grandes ciudades medias), ATIs intermedias (ciudades medias) y ATIs menores (ciudades medias menores). ${ }^{5}$

En el período 1991-2010 el conjunto de las ATIs del país registró un crecimiento demográfico cercano a un $41 \%$, una variación de $22,7 \%$ en el período intercensal $1991-2001$ y $14,8 \%$ en el período siguiente. Por su parte las ciudades intermedias de la Provincia de Buenos Aires registraron un incremento significativamente menor; puesto que en el período $1991-2010$ crecieron $19,5 \%{ }^{6}$

La ciudad de Bahía Blanca pertenece al grupo de ATls intermedias. Al observar su comportamiento demográfico, se puede apreciar que registra las menores variaciones intercensales del conjunto de ATIs bonaerenses, con tasas inferiores a la provincial y significativamente menores a los valores registrados en el país. Dentro de esta categoría, presenta un incremento similar a la localidad de San Nicolás y contrasta con la evolución experimentada por la ciudad de Tandil.

\footnotetext{
${ }^{5}$ ATIs mayores de 400.000 a 999.999 habitantes; ATIs intermedias de 100.000 a 399.999 habitantes, y ATIs menores de 50.000 a 99.999 habitantes (Di Nucci y Linares, 2016).

${ }^{6}$ Lindenboim y Kennedy (2004), en su estudio de la dinámica urbana en Argentina en el período 1960-2001, incluyen en la categoría de intermedias ciudades de 5.000 a 499.999 mil habitantes. Refiriéndose a la región pampeana y al Gran Buenos Aires, los autores sostienen que "desde la década del ochenta, las regiones más pobladas del país resultan a su vez la menos dinámicas en lo que a ritmo de crecimiento de la población respecta." (2004: 29). Y agregan que "los núcleos más dinámicos en la evolución del sistema de asentamiento urbano argentino son los intermedios extra pampeanos" (2004: 37).
} 


\begin{tabular}{|c|c|c|c|c|c|c|c|}
\hline \multirow{2}{*}{\multicolumn{2}{|c|}{ Aglomeraciones de tamaño intermedio (ATIs) }} & \multicolumn{3}{|c|}{ Población (en miles) } & \multicolumn{3}{|c|}{ Variación relativa intercensal (en \%) } \\
\hline & & \multirow{2}{*}{$\begin{array}{r}\text { Año } 1991 \\
643 \\
\end{array}$} & \multirow{2}{*}{$\begin{array}{r}\text { Año } 2001 \\
694 \\
\end{array}$} & \multirow{2}{*}{$\begin{array}{r}\text { Año } 2010 \\
800\end{array}$} & \multirow{2}{*}{$\begin{array}{c}1991-2001 \\
8,0\end{array}$} & \multirow{2}{*}{\begin{tabular}{|c|}
$2001-2010$ \\
15,2 \\
\end{tabular}} & \multirow{2}{*}{$\begin{array}{c}1991-2010 \\
24,3 \\
\end{array}$} \\
\hline ATla mavorec & Gran La Plata & & & & & & \\
\hline & Mar del Plata & 513 & 564 & 593 & 9,9 & 5,1 & 15,6 \\
\hline \multirow{3}{*}{$\begin{array}{l}\text { ATIs } \\
\text { intermedias }\end{array}$} & Bahía Blanca & 260 & 275 & 291 & 5,5 & 6,1 & 11,9 \\
\hline & San Nicolás & 119 & 125 & 134 & 5,1 & 6,5 & 12,0 \\
\hline & Tandil & 91 & 101 & 116 & 11,0 & 14,9 & 27,5 \\
\hline \multirow{6}{*}{$\begin{array}{l}\text { ATIs } \\
\text { menores }\end{array}$} & Zárate & 80 & 86 & 98 & 7,5 & 14,0 & 22,5 \\
\hline & Luján & 68 & 78 & 97 & 14,7 & 24,4 & 42,6 \\
\hline & Pergamino & 79 & 85 & 91 & 7,6 & 7,1 & 15,2 \\
\hline & Olavarría & 75 & 83 & 89 & 10,7 & 7,2 & 18,7 \\
\hline & Junín & 75 & 82 & 87 & 9,3 & 6,1 & 16,0 \\
\hline & Azul & 48 & 53 & 55 & 10,4 & 3,8 & 14,6 \\
\hline \multicolumn{2}{|c|}{ Total Población ATIs Pcia. Buenos Aires } & 2.051 & 2.226 & 2.450 & 8,5 & 10,1 & 19,5 \\
\hline \multicolumn{2}{|c|}{ Total Población ATIs de Argentina } & 8.583 & 10.529 & 12.084 & 22,7 & 14,8 & 40,8 \\
\hline
\end{tabular}

Población de aglomeraciones de tamaño intermedio bonaerenses (ATIs) y variación relativa intercensal, 1991, 2001 y 2010 Elaboración propia sobre la base de Di Nucci y Linares (2016)

\section{BAHÍA BLANCA: CRECIMIENTO DEMOGRÁFICO LENTO Y EXPANSIÓN URBANA}

Los guarismos censales muestran una desaceleración del ritmo de crecimiento poblacional de la ciudad y del partido de Bahía Blanca, y una variación relativa intercensal muy moderada, cercana al $6 \%$ en el período 2001-2010. ${ }^{7}$ No obstante, la evolución del número de viviendas y hogares de la ciudad verifica un mayor incremento, superior al 19\% en cada caso. Este crecimiento de la cantidad de hogares ha sido absorbido por la extensión de la periferia así como también por los nuevos edificios construidos en el área central y la ocupación de las unidades habitacionales ya existentes. ${ }^{8}$

\begin{tabular}{|c|c|c|c|c|}
\hline \multirow[b]{2}{*}{ Año } & \multicolumn{2}{|c|}{ Partido de Bahía Blanca } & \multicolumn{2}{|c|}{ Ciudad de Bahía Blanca } \\
\hline & $\begin{array}{c}\text { Población } \\
\text { total }\end{array}$ & $\begin{array}{l}\text { Variación } \\
\text { relativa \% }\end{array}$ & $\begin{array}{c}\text { Población } \\
\text { total }\end{array}$ & $\begin{array}{l}\text { Variación } \\
\text { relativa \% }\end{array}$ \\
\hline 1960 & 153.631 & \multirow{6}{*}{$\begin{array}{c}28,7 \\
18,4 \\
16,3 \\
4,5 \\
5,8\end{array}$} & 126.669 & \multirow{2}{*}{$\begin{array}{l}43,8 \\
22,9\end{array}$} \\
\hline 1970 & 197.680 & & 182.158 & \\
\hline 1980 & 234.047 & & 223.818 & 16,2 \\
\hline 1991 & 272.191 & & 260.096 & 5,5 \\
\hline 2001 & 284.776 & & 274.509 & 6,1 \\
\hline 2010 & 301.572 & & 291.327 & \\
\hline
\end{tabular}

Población total y variación relativa intercensal del partido y ciudad de Bahía Blanca

Elaboración propia en base a INDEC, Censo Nacional de Población, Hogares y Viviendas, y MBB (2000)

\footnotetext{
${ }^{7}$ La población total del partido comprende la población rural, y urbana de las localidades de Bahía Blanca, Ing. White, Gral. Cerri y Cabildo. La población de la ciudad de Bahía Blanca incluye la localidad portuaria de Ing. White.

${ }^{8}$ En febrero de 2008 se estimaba que en los últimos 5 años se habían construido más de cien edificios destinados a viviendas multifamiliares en dos barrios del macrocentro de la ciudad (Diario La Nueva, 13/2/2008).
} 


\begin{tabular}{|c|c|c|c|c|c|c|c|c|c|c|c|c|c|}
\hline \multirow[b]{2}{*}{ Año } & \multirow[b]{2}{*}{ Pobl. } & \multirow[b]{2}{*}{ Hogar. } & \multirow[b]{2}{*}{ Viv. } & \multirow{2}{*}{$\begin{array}{c}\text { Superf. } \\
\text { urbana } \\
\text { ocupada } \\
\text { (ha) }\end{array}$} & \multirow[b]{2}{*}{$\begin{array}{l}\text { Dens. } \\
\text { (hab./ha) }\end{array}$} & \multicolumn{4}{|c|}{$\begin{array}{c}\text { Variación relativa intercensal } \\
(\text { en \%) }\end{array}$} & \multicolumn{4}{|c|}{$\begin{array}{c}\text { Variación relativa 1991-2010 } \\
\text { (en \%) }\end{array}$} \\
\hline & & & & & & Pobl. & Hogar. & Viv. & $\begin{array}{l}\text { Superf. } \\
\text { urbana } \\
\text { ocupada }\end{array}$ & Pobl. & Hogar. & Viv. & $\begin{array}{c}\text { Superf. } \\
\text { urbana } \\
\text { ocupad } \\
\text { a }\end{array}$ \\
\hline 1991 & 260.096 & 78.654 & 76.123 & 3.416 & 76 & \multirow{3}{*}{$\begin{array}{l}5,54 \\
6,13\end{array}$} & \multirow{3}{*}{$\begin{array}{l}12,21 \\
19,35\end{array}$} & \multirow{3}{*}{$\begin{array}{l}11,97 \\
19,21\end{array}$} & \multirow{3}{*}{$\begin{array}{l}64,2 \\
14,9\end{array}$} & \multirow{3}{*}{12,01} & \multirow{3}{*}{33,93} & \multirow{3}{*}{33,47} & \multirow{3}{*}{88,8} \\
\hline 2001 & 274.509 & 88.260 & 85.233 & 5.611 & 49 & & & & & & & & \\
\hline 2010 & 291.327 & 105.342 & 101.605 & 6.449 & 45 & & & & & & & & \\
\hline
\end{tabular}

Variación relativa intercensal de población, vivienda, hogares y superficie urbana ocupada de la ciudad de Bahía Blanca, años 1991, 2001 y 2010

Elaboración propia en base a INDEC (1991, 2001 y 2010) y Ministerio del Interior, Obras Públicas y Vivienda (2016)

En este contexto resulta oportuno señalar que en el año 2010 casi el $8 \%$ de las viviendas particulares de la ciudad fue registrado con todas las personas temporalmente ausentes, cifra que implica más de 9.500 viviendas desocupadas al momento del censo (INDEC, 2010). En tanto en el año 2016 más de 10 mil familias se encontraban inscriptas en el Registro Único de Postulantes (RUP), que es una base de datos unificada de la demanda de lotes y vivienda del partido de Bahía Blanca. ${ }^{9}$ Las cifras presentadas anteriormente plantean ciertos interrogantes sobre el crecimiento de la construcción, la expansión urbana, la dinámica del mercado inmobiliario y la demanda habitacional en la ciudad.

\subsection{Expansión urbana discontinua}

Al recorrer la periferia de la ciudad o al observar una imagen satelital se puede apreciar el proceso de extensión de la superficie urbana de manera discontinua y en baja densidad. Mientras la expansión de la ciudad ha traspasado el Anillo de Circunvalación Externa, al interior de este "límite" artificial permanecen importantes superficies de tierras sin ocupar que interrumpen la mancha urbana.

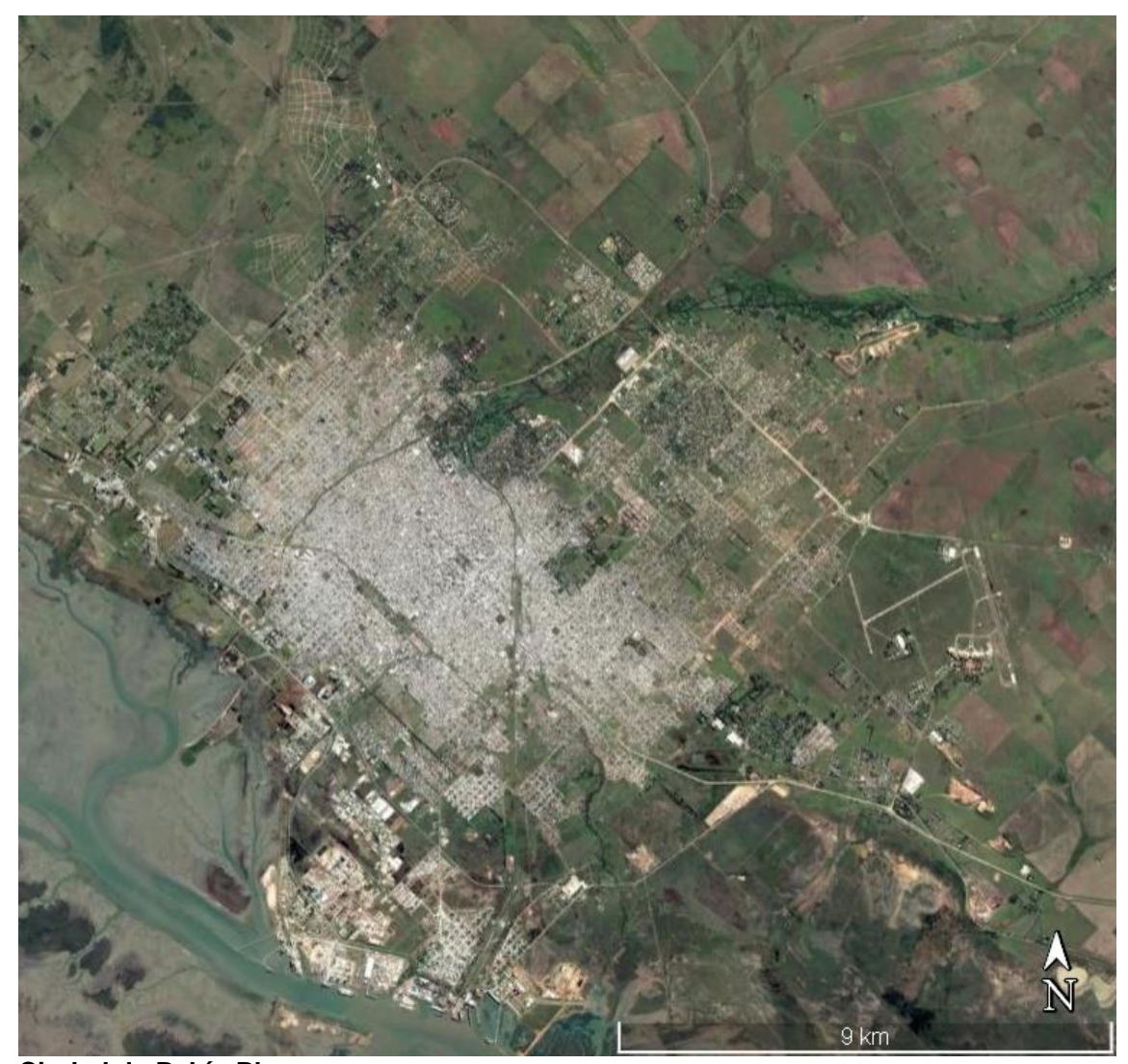

Ciudad de Bahía Blanca

Google Earth

${ }^{9}$ http://gabierto.bahiablanca.gob.ar/datos-abiertos/agencia-urbana/tierras-y-viviendas/mas-barrios-sorteos-de-tierras-yviviendas/registro-unico-de-postulantes/ 
En el año 2014, el gobierno local realizó un relevamiento que involucraba fracciones o macizos de suelo indiviso, y antiguos loteos que tuvieron nula o escasa ocupación. Contabilizó en esa oportunidad 9.014 inmuebles baldíos que comprendían una superficie de 1.772 ha. ${ }^{10}$ Asimismo existen tierras fiscales que, debido a su superficie y localización, generan interrupciones en el tejido urbano. En este sentido, se destacan 360 hectáreas del Ejército Argentino y 150 ha. pertenecientes a la Universidad Nacional del Sur, así como también tierras nacionales y provinciales en el sector sur y sudoeste de la ciudad (aproximadamente 350 ha.). ${ }^{11}$

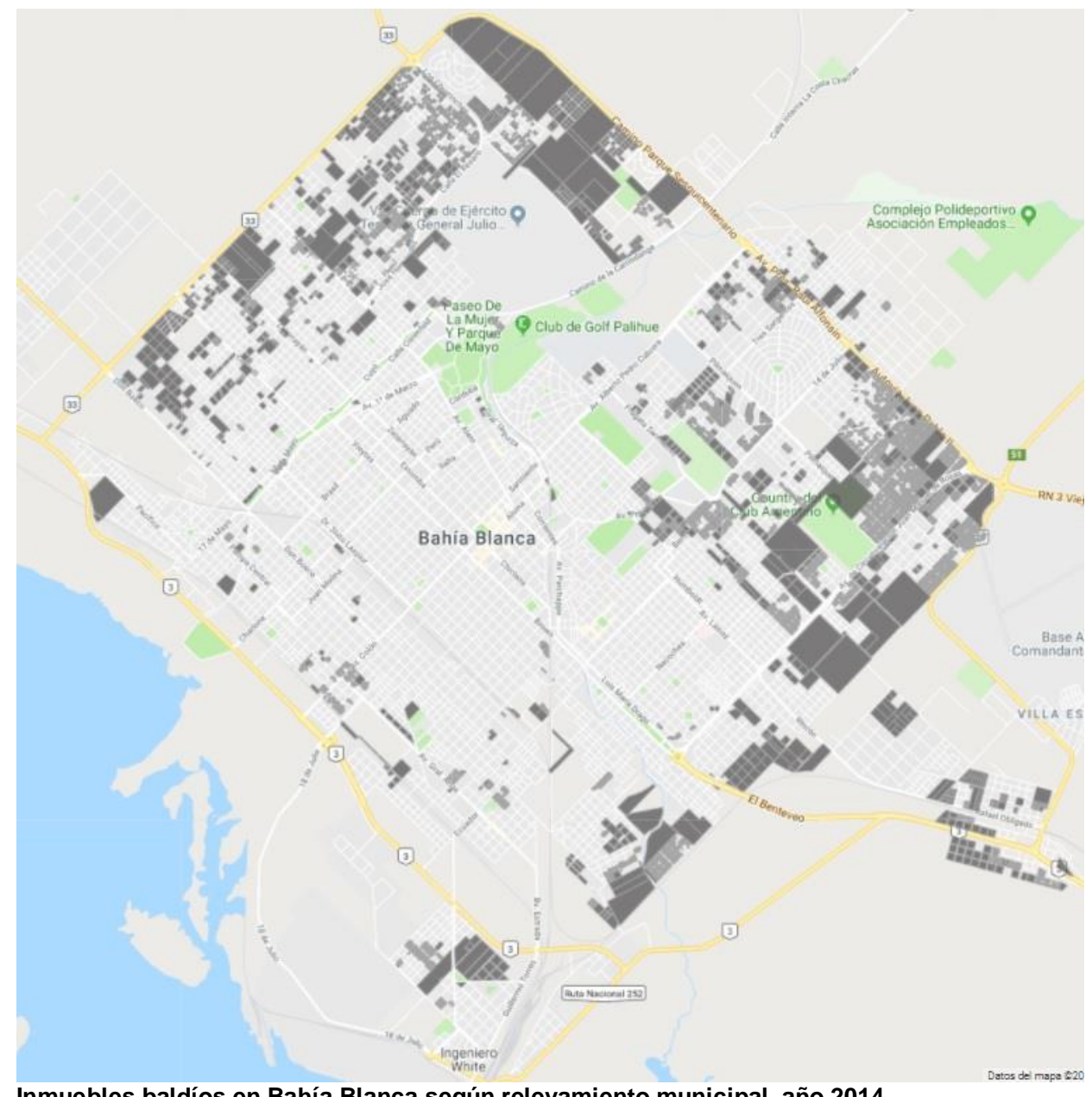

Inmuebles baldíos en Bahía Blanca según relevamiento municipal, año 2014

http://gabierto.bahiablanca.gob.ar/mapa/movilidad-de-suelos/

Se efectuó una primera aproximación al estudio de la evolución de la superficie urbanizada en el período intercensal 1991-2010 sobre la base del trabajo realizado por la Subsecretaría de Planificación Territorial del Ministerio del Interior, Obras Públicas y Vivienda (2016). ${ }^{12}$ Según los cálculos que se desprenden de esta información, en el período 1991-2010 la superficie urbana ocupada se incrementó un 89\%, mientras la población creció un 12\%. Se destaca un incremento de 64\% de la mancha urbana en el período 1991-2001 y un descenso significativo para el siguiente periodo intercensal, donde la variación de la superficie fue del $15 \%$. Atento a estas cifras, se puede apreciar un marcado descenso de la densidad promedio en la ciudad, de 76 habitantes por hectárea en el año 1991 a 45 hab./ha. en 2010.

\footnotetext{
${ }_{11}^{10}$ http://gabierto.bahiablanca.gob.ar/movilidad/doc/Ordenanza-Fiscal.pdf

11 Una importante superficie de tierras fiscales ha sido aprovechada para emplazar conjuntos habitacionales del Programa Federal de Construcción de Vivienda, y también se han cedido aproximadamente 1.600 lotes fiscales a familias de escasos recursos a través de los Programas Hábitat y Más Barrios.

${ }^{12}$ Se determinó la superficie urbanizada en base al análisis de imágenes satelitales Landsat 5 y 7 , provistas por la CONAE, que tienen una resolución espacial de 1 píxel = 30 × 30 metros. Para el procesamiento de las imágenes se utilizó el programa Erdas y se efectuó una clasificación de tipo supervisada a fin de identificar cuatro clases de coberturas: suelo urbano, suelo desnudo, vegetación y agua. Recuperado de: http://sig.planificacion.gob.ar/layers/buscar/?texto=bahia+blanca
} 


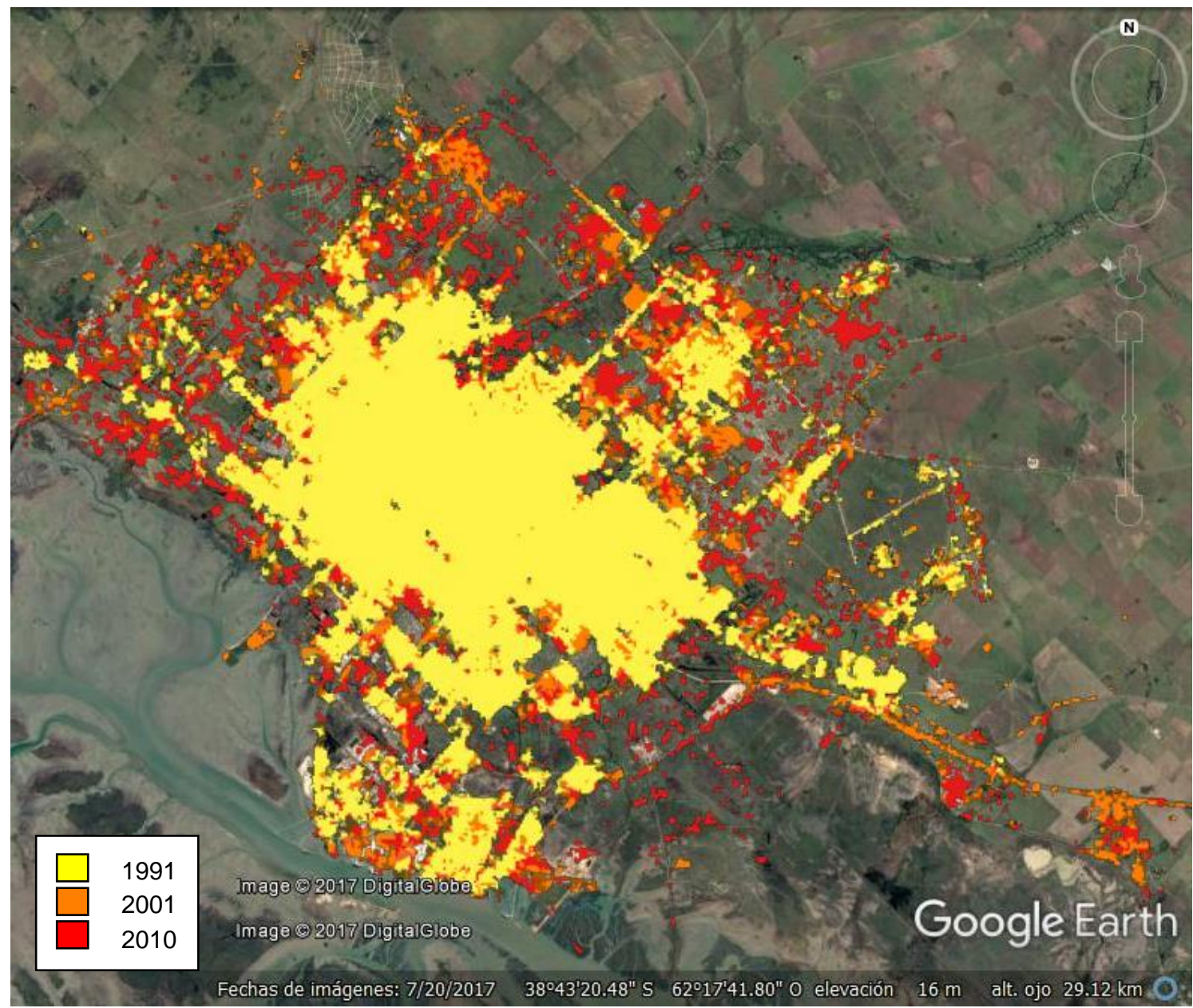

Evolución de superficie urbanizada de la ciudad de Bahía Blanca, años 1991, 2001 y 2010

Elaboración propia en base a Ministerio del Interior, Obras Públicas y Vivienda (2016) e imagen del Google Earth.

Estos datos proporcionados por una fuente secundaria son un punto de partida en el contexto de formulación del proyecto de tesis. Sin duda el análisis de la evolución de la expansión urbana a partir del procesamiento e interpretación de imágenes satelitales constituirá un insumo necesario que se llevará a cabo en el marco del desarrollo de la tesis. Asimismo se procesarán datos censales de 1991, 2001 y 2010 a nivel de radio mediante el uso de un sistema de información geográfica (SIG), de tal modo de poder realizar un análisis espacial de diferentes variables poblacionales y habitacionales. ${ }^{13}$

\subsection{Tipologías de tejidos residenciales}

La expansión de la ciudad se materializa de distintas maneras y se observan diferentes características morfológicas y socioeconómicas en el proceso de ocupación y configuración urbana de los distintos sectores de la periferia. A partir de la interpretación de la imagen satelital y la información aportada por otras fuentes, se puede establecer, en una primera aproximación, las siguientes tipologías de tejido residencial, que serán revisadas y ajustadas mediante el análisis de un conjunto de indicadores en el desarrollo de la investigación doctoral.

Loteo tipo barrio parque: El Código de Planeamiento Urbano de 1993 asignó como uso dominante para la zona alta, en la franja norte-noreste-este, el residencial parque de densidad baja en dos tipologías de tejido urbano, Rp1 y Rp2. En este sector de la ciudad se concentran la mayor parte de loteos tipo barrio parque que, desarrollados generalmente por agentes inmobiliarios, ofrecen terrenos con servicios y, en algunos casos, forestación.

A pesar que han absorbido una importante demanda en las dos últimas décadas, se puede observar que

${ }^{13}$ Según el INDEC, un radio es una unidad censal con límites geográficos y una determinada cantidad de unidades de viviendas a relevar. Un radio tiene un promedio de 300 viviendas, cifra que puede bajar a 200 en el caso de los radios urbanos en los bordes de las localidades. Cierta cantidad de radios conforman una fracción censal que tiene un promedio de 5000 viviendas. 
una importante proporción de la oferta aún permanece sin ser ocupada. Los loteos relevados hasta el momento comprenden más de 3.900 parcelas (de 400 a $3.000 \mathrm{~m}^{2}$ ) y una superficie de 400 hectáreas.
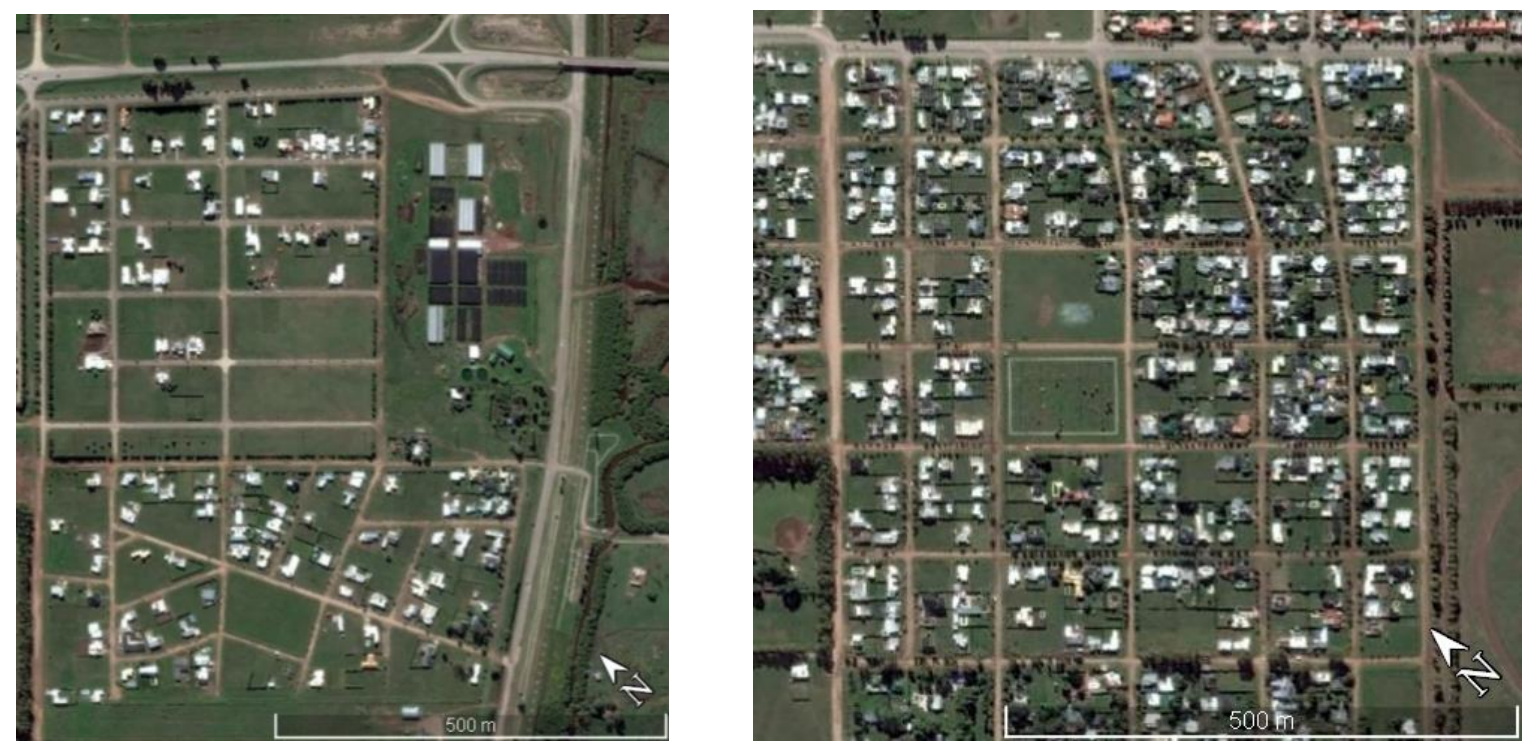

Loteos tipo barrio parque

Google Earth

Urbanizaciones cerradas: Existen tres urbanizaciones cerradas -Bosque Alto, Solares Norte y La Reservaen el sector norte que incorporaron 716 parcelas (de 600 a $1.500 \mathrm{~m}^{2}$ ) al submercado del suelo destinado a la población de ingresos medio-alto y alto, y ocupan una superficie de aproximadamente 99 hectáreas.
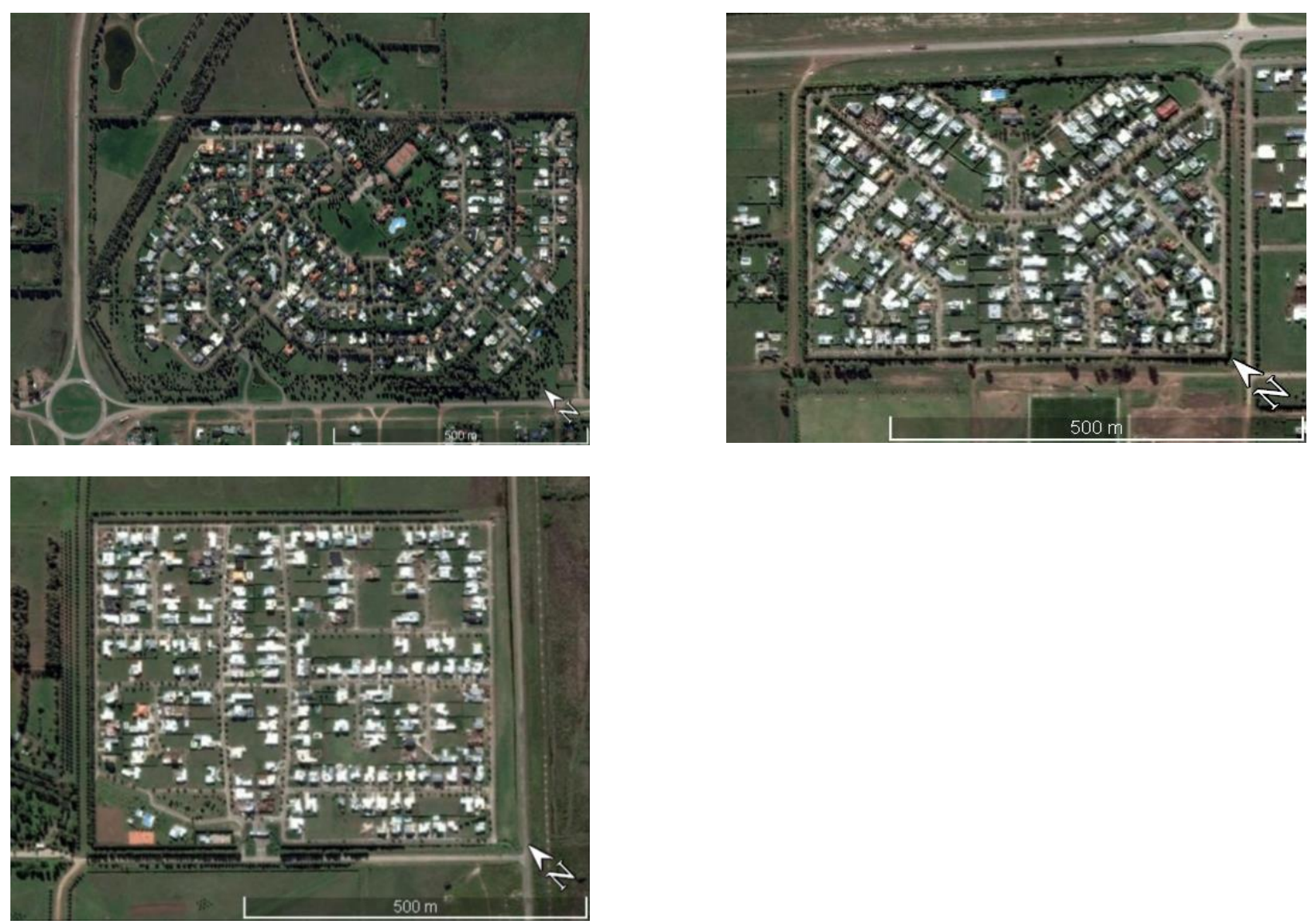

Urbanizaciones cerradas en Bahía Blanca Google Earth 
Periurbano calificado: El Plan Director del Periurbano Bahiense, sancionado por Ordenanza № 15637 del año 2010, creó el distrito periurbano calificado (PUC) destinado al uso residencial de baja densidad de ocupación, con subdivisión mínima de 1.000 y $2.500 \mathrm{~m}^{2}$ (FOS y FOT de 0,40), en el sector NO-N-NE contiguo al Anillo de Circunvalación Externa. En el marco de este plan se aprobaron dos loteos de Graciela Ivars - Desarrollos Urbanos S.A. en el sector norte de la ciudad, más allá de la Circunvalación. "Campos de Alem" dispone de 1.161 parcelas de hasta $1.000 \mathrm{~m}^{2}$ en un predio de 186,5 hectáreas en el Camino Sesquicentenario; y "La Huella", ubicado en un sector conocido como Cueva de los Leones, ofrece 751 parcelas de $2,500 \mathrm{~m}^{2}$ en un emprendimiento de 344,5 hectáreas sobre la ruta Nacional $\mathrm{N}^{\circ} 33$.

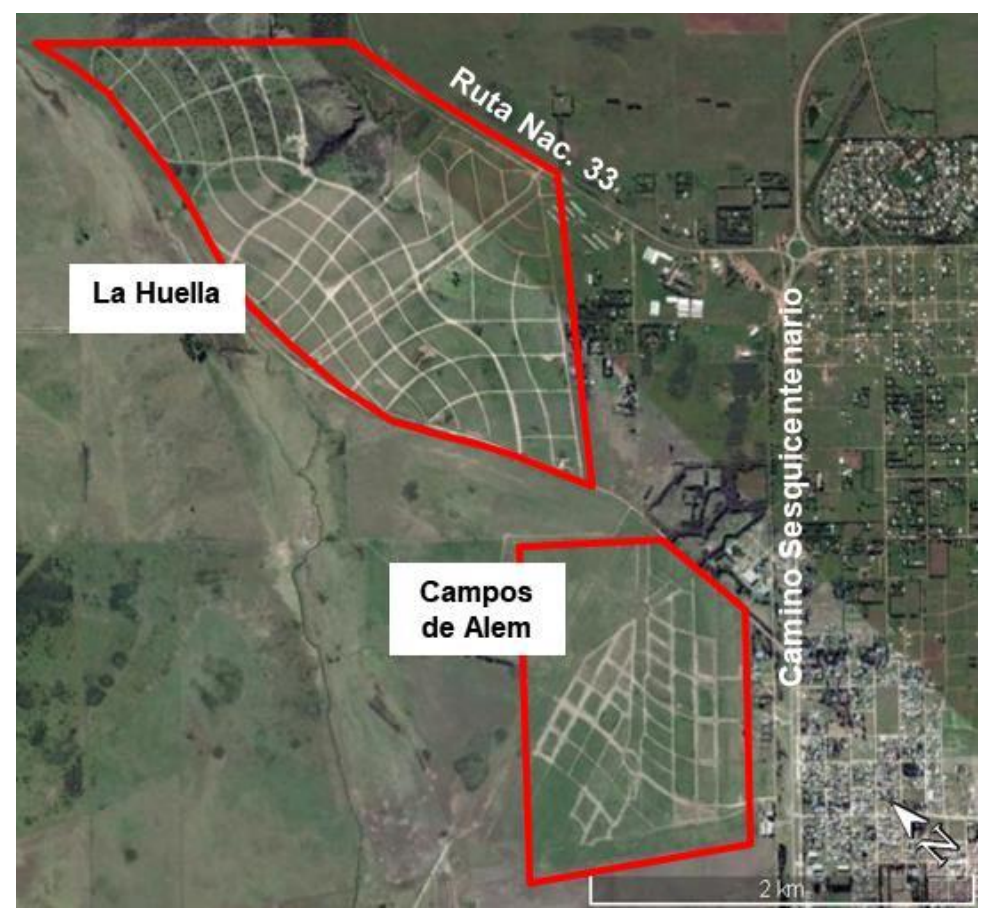

Loteo en el distrito periurbano calificado

Elaboración propia sobre la imagen de Google Earth

Villas y asentamientos precarios: según el Registro Público Provincial existen 32 villas y asentamientos precarios en la ciudad de distinta data que evidencian diferente grado de consolidación y condiciones habitacionales (RPPVAP, 2015). Sin duda la ocupación de tierras de manera informal y el crecimiento de los asentamientos ha contribuido a la extensión de la mancha urbana. Se localizan fundamentalmente en la franja oeste-sudoeste-sur, en muchos casos sobre tierras fiscales.

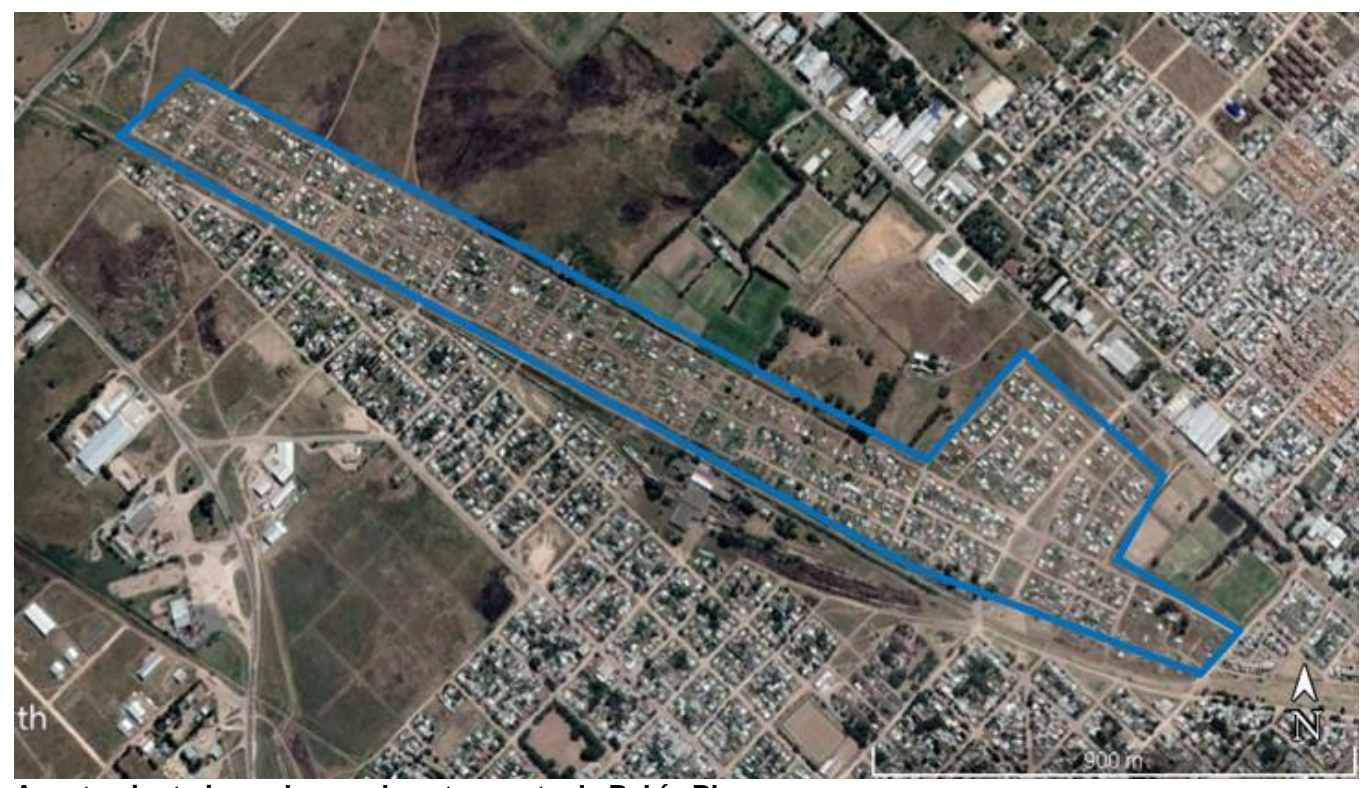

Asentamiento irregular en el sector oeste de Bahía Blanca

Elaboración propia sobre la imagen de Google Earth (2017) y el RPPVAP (2015) 
Conjuntos habitacionales y planes de vivienda social: se ha construido un número importante de conjuntos habitacionales en la ciudad a través de distintas operatorias, en algunos casos llevadas adelante por entidades intermedias (Sindicatos, Asociaciones, Cooperativas) y en otros por organismos estatales. En su gran mayoría se localizaron en los sectores noroeste y sur, y en menor medida en el este.

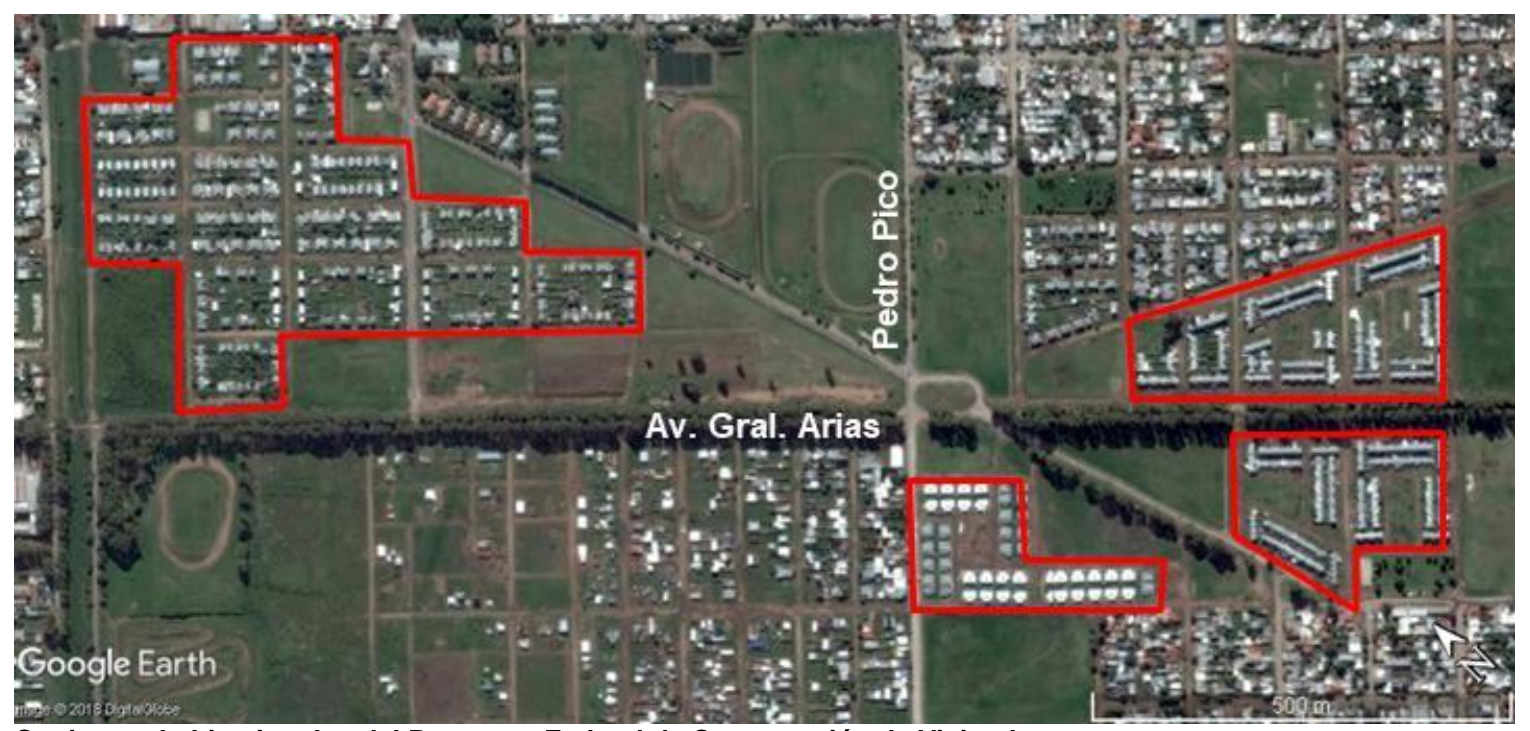

Conjuntos habitacionales del Programa Federal de Construcción de Vivienda

Elaboración propia sobre la imagen de Google Earth

Crecimiento disperso de vivienda individual: En distintos sectores de la periferia se observa la construcción de viviendas unifamiliares en parcelas de antiguos loteos, conformando un tejido disperso. Se trata de operaciones individuales que realizan las familias, generalmente en el mercado formal, de acuerdo a sus posibilidades económicas. La urbanización del área se desarrolla de forma paulatina a medida que los terrenos del sector se van ocupando. Muchas veces el tiempo transcurrido entre la subdivisión de la tierra, la adquisición familiar del terreno con el fin de construir y la materialización de la construcción es prolongado. El proceso de ocupación y consolidación urbana del sector insume generalmente varios años, incluso décadas.

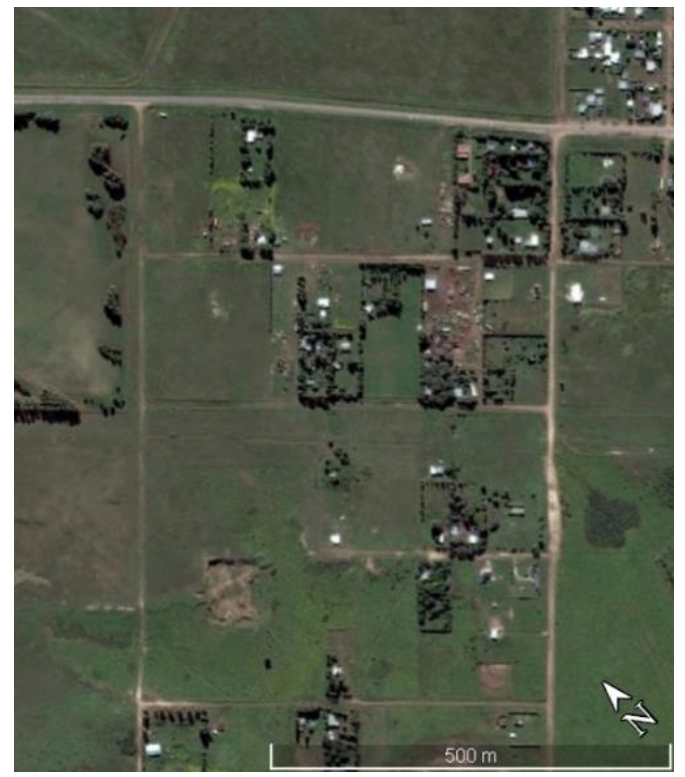

Crecimiento en el sector este de la ciudad.

Google Earth

En síntesis, se puede observar la conformación de áreas diferenciadas: una periferia ocupada por los estratos alto y medio con una fisonomía de "suburbio verde" y unifamiliar en el norte-noreste (zona alta); una periferia más densa de conjuntos habitacionales y viviendas de estrato medio y medio-bajo en el noroeste y este; y una periferia de escasos recursos que crece en la franja oeste-sudoeste-sur (zona baja), donde las condiciones en términos de calidad urbana, dotación de infraestructura y equipamiento, accesibilidad y 
articulación con la ciudad son claramente inferiores y en algunos casos deficientes. Ello no implica que dentro de estas grandes áreas no resida población de un nivel de socioeconómico diferente, especialmente en los sectores urbanos de mejores ingresos.

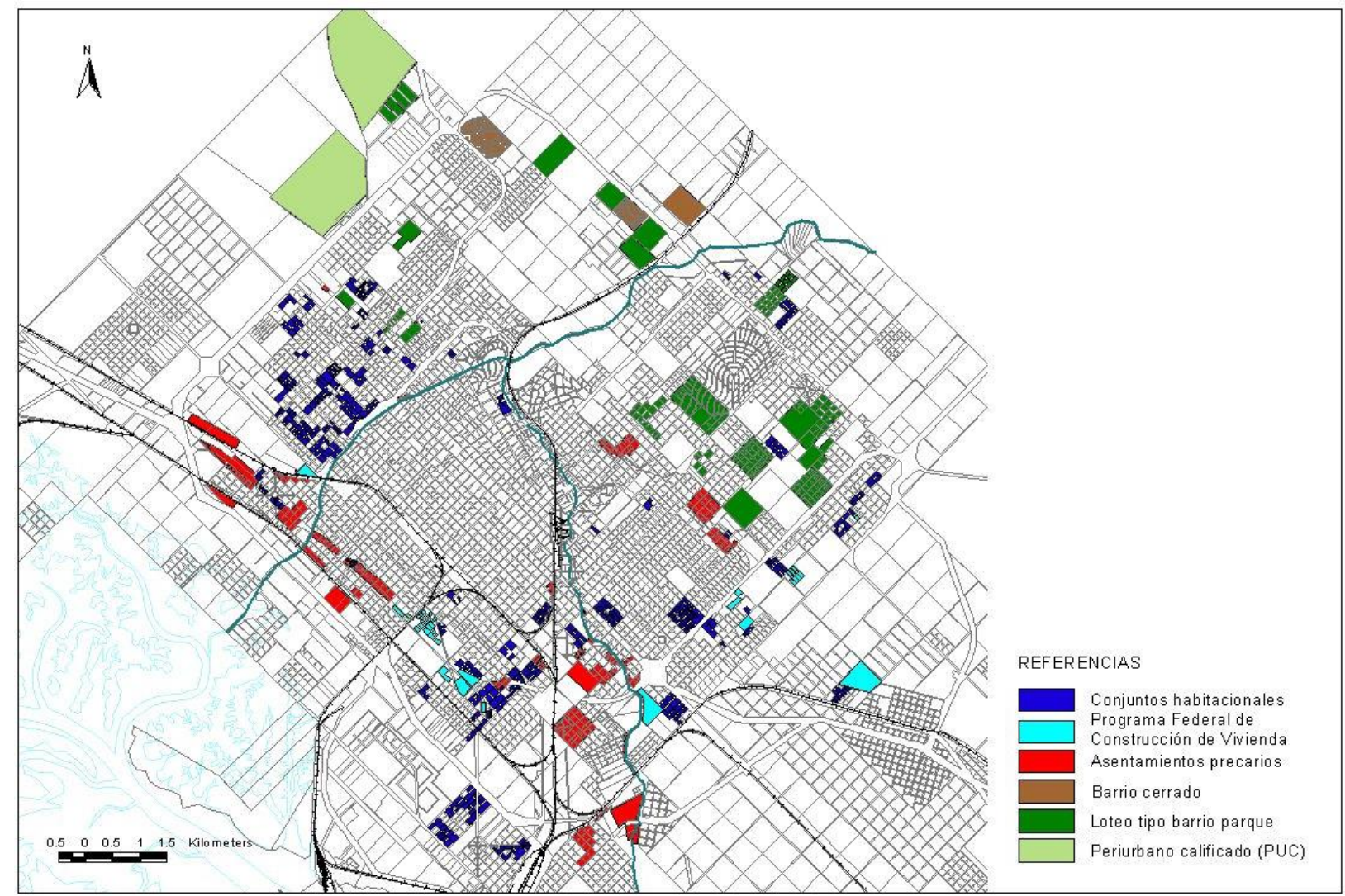

Conjuntos habitacionales, loteos privados y asentamientos precarios en Bahía Blanca Elaboración propia.

\section{EL GOBIERNO LOCAL Y LA EXPANSIÓN DE BAHÍA BLANCA DESDE LA PERSPECTIVAS DE LOS PLANES URBANOS (1970-2010)}

Bahía Blanca cuenta con una importante trayectoria en materia de planificación urbana y sus primeros antecedentes de ordenamiento se remontan a principios del siglo XX. Los distintos planes urbanos tuvieron una mirada sobre el crecimiento de la ciudad y la disponibilidad de tierras para absorberlo.

El Plan de Desarrollo del año 1971 sostenía la hipótesis de un polo regional en franca expansión, no obstante propuso no extender los fraccionamientos urbanos, atento a la cantidad de amanzanamientos no materializados. La existencia de amplias superficies fraccionadas sin uso urbano en la periferia se remonta a las primeras décadas del siglo XX cuando se subdividió, debido a un interés especulativo, una importante cantidad de tierras que permaneció prácticamente sin ocupación efectiva durante varias décadas (MBB, 1971). Este proceso de subdivisión indiscriminada de la tierra fue controlado, en cierta medida, por la sanción en el año 1977 del Decreto-Ley N 8912 de Ordenamiento territorial y uso del suelo de la Provincia de Buenos Aires. ${ }^{14}$

Por su parte, la Reformulación del Plan de Desarrollo (1986) estimó que existía potencialmente una cantidad suficiente de tierra urbanizada para cubrir en principio las demandas futuras. Por tal motivo, afirmó que "Sería conveniente establecer límites urbanos claramente identificables para evitar el crecimiento indiscriminado de la ciudad." (MBB, 1986: 31). Como producto de esta Reformulación, se diseñó un nuevo Código de Zonificación que entró en vigencia en 1993. Este dividió a la ciudad en fajas longitudinales respetando el soporte natural, modelo territorial que explica, en gran medida, la configuración socioespacial, funcional y morfológica actual de Bahía Blanca. Se establecieron tres grandes zonas: la meseta, definida

\footnotetext{
${ }^{14}$ El Decreto-ley rige el ordenamiento del territorio, y regula el uso, ocupación, subdivisión y equipamiento del suelo en los municipios de la Provincia de Buenos Aires. Entre los objetivos fundamentales señala la implantación de los mecanismos legales, administrativos y económico-financieros que posibiliten la eliminación de los excesos especulativos (art 2 inc. e).
} 
principalmente como un área residencial de baja densidad con tejido abierto; la planicie central donde se asientan los ejes de crecimiento con usos comerciales y viviendas de densidades medias y la zona residencial mixta, y finalmente el área costera, reservada principalmente a usos industriales de envergadura y actividades portuarias. De este modo se pretendía inducir un cambio sustancial en la conformación del espacio urbano, pues se planteó un desarrollo lineal en función de ejes longitudinales para compensar la atracción y concentración de actividades existentes en el área central.

Atento al objetivo de contener la expansión de la ciudad, el Código propuso entre sus lineamientos generales revertir el proceso de crecimiento disperso y "tener en cuenta el alto porcentaje de subdivisiones prematuras de tipo urbano existentes." (MBB, 1993). No obstante, el proceso de urbanización discontinuo prosiguió y el crecimiento se extendió más allá de la Circunvalación. Tanto es así que el Plan Estratégico del año 2000 reconoció esta situación como una de las principales debilidades de Bahía Blanca: "La ciudad se ha extendido de manera poco controlada, con un patrón de ocupación del suelo discontinuo y de baja densidad, condicionando la calidad de vida de importantes sectores de la periferia urbana" (MBB, 2000: 105). Se estableció entonces como eje estratégico el "Mejoramiento de la calidad urbano ambiental de la ciudad a través de la revalorización del área central, la integración a la trama de las tierras vacantes del Estado y el crecimiento ordenado de la periferia". En este contexto, el Programa de gestión urbano ambiental del Plan contempló, dentro de la cartera de proyectos consensuados con la comunidad bahiense, la actualización del Código de Planeamiento Urbano, el fortalecimiento de las centralidades barriales, un plan integral para los asentamientos irregulares y precarios, y un plan director de infraestructura urbana, entre otras propuestas. El Plan Estratégico fue desestimado por el gobierno que asumió en diciembre del año 2003.

En el año 2008 a fin de llevar a cabo la actualización del Código de Planeamiento Urbano de 1993, se conformó la Unidad de Reformulación que elaboró propuestas de ordenamiento para diferentes sectores de la ciudad. Una de ellas es el denominado Plan Director del Periurbano Bahiense y Centros de Interés Turístico Ambiental (CITA). La formulación de este Plan instaló el debate sobre la existencia (o no) de vacíos en condición de ser ocupados en la ciudad y la necesidad (o no) de ampliar la zona destinada a usos urbanos. ${ }^{15}$

Sancionado en mayo de 2010 (Ordenanzas № 15637 y 16249), planteó "Instrumentar un mecanismo de habilitación de desarrollos suburbanos en concurso de propuestas, destinados a receptar el aumento poblacional y a ampliar la oferta de suelo, con calidad en materia de espacios públicos y áreas de servicio a la ciudad"16. Propuso incrementar la oferta (física) de suelo puesto que se consideró que "el suelo aún sin fraccionar de propiedad de particulares disponibles dentro del llamado ejido alcanza hoy sólo a un $7 \%$ del total de la superficie"; ello suponía casi 800 hectáreas vacantes para ser fraccionadas. La ordenanza no menciona que, según un informe del Departamento de Catastro del año 2009, un 13\% de la superficie del ejido se encontraba "loteada a cubrir". Sin embargo reconoce que "un porcentaje significativo de suelo urbanizado dentro del ejido permanece ocioso, y en buena medida se halla por completo fuera del tráfico inmobiliario". ${ }^{17}$

Mediante este Plan se creó el distrito periurbano calificado (PUC) destinado al uso residencial de baja densidad de ocupación, con subdivisión mínima de 1.000 y $2.500 \mathrm{~m}^{2}$ (FOS y FOT de 0,40), en el sector NON-NE contiguo al Anillo de Circunvalación Externa, en un área de gran valor paisajístico. Claramente esta tipología de periurbano responde a las tendencias del mercado y la valorización inmobiliaria evidenciadas en las últimas décadas en la zona alta de la ciudad. ${ }^{18}$

En este contexto resulta oportuno señalar que el gobierno local cumple un rol clave, por acción y/u omisión, en el proceso de crecimiento de la ciudad. Interviene de diversas maneras, mediante la regulación del uso y ocupación del suelo, la creación de infraestructura y equipamiento, la ejecución de programas de vivienda social, entre otras formas. En este apartado se mencionó muy brevemente la expansión de la ciudad desde

\footnotetext{
${ }^{15}$ Cabe señalar algunos titulares del Diario La Nueva: "Dilemas del planeamiento. ¿Una segunda ciudad, cuando la primera está a medio llenar?" (13/12/2009); “¿Llenar espacios vacíos o irse más lejos?” (4/1/2010); “La polémica del periurbano ¿Hacia dónde orientar el planeamiento de la ciudad de Bahía Blanca?” (4/4/2010); “Desarrollo y accesibilidad al suelo. ¿Sí o no al periurbano?” (18/4/2010).

${ }^{16}$ La nueva zonificación involucra fundamentalmente una superficie de 3.844 ha. de tierra designada como "periurbano calificado" (PUC) y 1.642 ha. como "periurbano a reestructurar" (PUR). La Ordenanza 15637 establece la existencia de un cupo urbanizador para los usos residenciales que se habilitará quinquenalmente mediante un concurso de propuestas de desarrollo.

${ }^{17}$ Según la información catastral, en el año 2009 existían 2.200 hectáreas privadas vacantes al interior del ejido urbano (11 mil ha.). Esta cifra resulta de la sumatoria de 783 ha de vacíos privados reales y un 13\% del ejido loteado a cubrir (1.430 ha aproximadamente).

${ }^{18}$ En febrero de 2011 el Honorable Concejo Deliberante aprobó por mayoría el primer cupo urbanizador de 4.200 nuevas parcelas (Decreto 1672/2010 del Departamento Ejecutivo) y en noviembre de ese mismo año se abrió el concurso de propuestas de desarrollo, las cuales fueron presentadas en marzo de 2012.
} 
la perspectiva de los últimos planes urbanos, sin dejar de reconocer la importancia que reviste otras acciones, por ejemplo las inversiones en obras públicas (viales, de infraestructura de servicios, de vivienda social, etc.) que serán analizadas en el marco de la investigación doctoral.

Más allá de sus intenciones y apreciaciones sobre el crecimiento y la disponibilidad de tierras urbanizables, los planes formulados no ejercieron un control efectivo sobre la expansión urbana y la ocupación de la periferia. El Código de Planeamiento de 1993 propuso un modelo de ciudad caracterizado por un sector vinculado al uso industrial-portuario, de carácter residencial mixto; una faja central de mayor densidad y diversidad de usos, y una faja alta de uso residencial de baja densidad (residencial parque) que se evidencia desde el punto de vista de la morfología y estructura urbana resultante. En efecto el modelo de zonificación ha condicionado cierta diferenciación socioespacial del crecimiento urbano de Bahía Blanca. Por su parte el Plan Director del Periurbano del 2010 no sólo promueve el modelo de expansión en muy baja densidad y elevado consumo de suelo, sino que la tipología de desarrollo propuesta contribuye a la consolidación de la franja norte-noreste como un sector destinado principalmente a la población de mayor poder adquisitivo.

\section{REFLEXIONES FINALES}

Las tendencias del mercado -respaldadas por la normativa urbana- promueven un patrón de expansión urbana en muy baja densidad en la ciudad de Bahía Blanca. El fenómeno de crecimiento en extensión reviste gran importancia en función de sus condicionantes, sus consecuencias, su relación con la planificación, sus políticas de control, y fundamentalmente su impacto sobre la ciudad (Indovina, 2007). En este sentido es dable reconocer la necesidad de profundizar el estudio de las formas de expansión y crecimiento, sus causas y efectos, particularmente en ciudades intermedias, aún no tan analizadas como las grandes metrópolis.

En efecto, la mancha urbana de Bahía Blanca se extiende dentro y fuera de la Circunvalación, mientras deja superficies vacantes a su paso, evidenciando un proceso de expansión discontinuo. Las vías rápidas de comunicación constituyen un factor inductor de la urbanización al mejorar la accesibilidad y la comunicación entre la periferia y el área central, y un elemento transformador de la morfología periurbana.

El crecimiento más allá de estos vacíos ocasiona considerables disfuncionalidades; no sólo supone mayores costos económicos de funcionamiento y mantenimiento que debe asumir la ciudad en su totalidad, sino también contribuye a un proceso de fragmentación urbana y social. Por otra parte, resulta importante considerar que favorece la valorización de las tierras ociosas ubicadas entre las áreas de expansión y el área urbana consolidada, al mejorar su situación relativa, provocando el encarecimiento del suelo para los sectores de menores ingresos. Mientras tanto los propietarios de estas tierras obtienen un excedente y se benefician del accionar público y privado en el proceso de construcción urbana.

En el proceso de expansión urbana la población de altos ingresos se localiza en ciertos sectores de la periferia valorizados por la inversión, las expectativas de desarrollo, el entorno social, la oferta ambiental, la disponibilidad de amplias parcelas, la adecuada accesibilidad y dotación de infraestructura, entre otros factores; en tanto, algunos grupos sociales de escasos recursos no pueden participar en el mercado formal y "resuelven" su problema habitacional mediante la invasión de tierras en zonas menos favorecidas.

Para concluir, Bahía Blanca evidencia un proceso de diferenciación morfológica y socioespacial en el crecimiento de la ciudad, favorecido por el funcionamiento del mercado inmobiliario y la acción y/u omisión del Estado, entre otros factores. Parecería entonces que la periferia bahiense es un complejo mosaico de zonas diferenciadas por su nivel de ingreso, dotación de infraestructura y equipamiento, y articulación con la ciudad consolidada, así como también tierras vacantes a la espera de ser incorporadas efectivamente al proceso de urbanización.

\section{BIBLIOGRAFÍA}

AZÓCAR, G., SANHUEZA, R. y HENRÍQUEZ, C. (2003). Cambio en los patrones de crecimiento en una ciudad intermedia: el caso de Chillán en Chile Central. EURE (Santiago), 29 (87), 79-82.

BELLET, C. et al. (Eds.), (2015). Urbanización, producción y consumo en ciudades medias/intermedias. Presidente Prudente: Universidade Estadual Paulista; Lleida: Edicions de la Universitat de Lleida. 
BELLET, C. y LLOP J. M. (2004) Miradas a otros espacios urbanos: Las ciudades intermedias. Revista electrónica de geografía y ciencias sociales. Vol. VIII, No. 165.

CÁRDENAS ROPERO, F. (2012). Ciudad compacta-ciudad eficiente. En X. VÁZQUEZ MAO (Ed.), Retos de la acción de gobierno para las ciudades del siglo XXI. Eixo Atlântico do Noroeste Peninsular (305-328)

CEBRIÁN ABELLÁN, F. y PANADERO MOYA, M. (Coords.) (2013). Ciudades medias: formas de expansión urbana. Madrid: Biblioteca Nueva.

CHAVOYA GAMA, J. et al (2009). Una reflexión sobre el modelo urbano: ciudad dispersa-ciudad compacta. 5th International Conference Virtual City and Territory, Barcelona.

DI NUCCI, J. y LINARES, S. (2016). Urbanización y red urbana argentina: un análisis del período 19912010. Journal de Ciencias Sociales. Buenos Aires, 4 (7), 4-17.

ENTRENA DURÁN, F. (2005). Procesos de periurbanización y cambios en los modelos de ciudad. Un estudio europeo de casos sobre sus causas y consecuencias. Papers. Revista de Sociologia, [S.I.], v. 78, oct. 2005, 59-88.

FREDIANI, J. (2010). Lógicas y tendencias de la expansión residencial en áreas periurbanas. El Partido de La Plata, Buenos Aires, Argentina, entre 1990 y 2010 (Tesis de postgrado). Presentada en Universidad Nacional de La Plata. Facultad de Humanidades y Ciencias de la Educación para optar al grado de Doctora en Geografía.

INDOVINA, F. (Coord.) (2007). La ciudad de baja densidad: lógicas, gestión y contención. Barcelona: Diputación Barcelona.

LINDENBOIM, J. y KENNEDY, D. (2004). Dinámica urbana Argentina. 1960-2001. Reconstrucción y análisis de la información necesaria. Documentos de Trabajo № 3. Buenos Aires: CEPED.

LLOP TORNÉ, J. M. (Dir.) (1999). Ciudades intermedias y urbanización mundial. Programa UIA-CIMES, Ajuntament de Lleida, UNESCO, UIA.

MAGRINYÀ, F. y HERCE, M. (2007). Los costes ambientales de la ciudad de baja densidad. En F. INDOVINA, (Coord.). La ciudad de baja densidad: lógicas, gestión y contención (243-264). Barcelona: Diputación de Barcelona.

MOLINÍ, F. y SALGADO, M. (2012). Los impactos ambientales de la ciudad de baja densidad en relación con los de la ciudad compacta. Biblio 3W. Revista Bibliográfica de Geografía y Ciencias Sociales. Barcelona: Universidad de Barcelona, Vol. XVII, № 958.

MONCLUS F. J. (Ed) (1998). La ciudad dispersa. Suburbanización y nuevas periferias. Barcelona: Centre de Cultura Contemporania de Barcelona.

MUNICIPALIDAD DE BAHÍA BLANCA (1971). Plan de Desarrollo de Bahía Blanca. Bahía Blanca.

--- (1986). Reformulación del Plan de Desarrollo de Bahía Blanca. Bahía Blanca.

--- (1993). Código de Planeamiento Urbano de Bahía Blanca. Bahía Blanca.

--- (2000). Plan Estratégico Bahía Blanca. Bahía Blanca.

--- (2009). Estudio de vacíos reales. Crecimiento y compleción de la mancha urbana y su relación con la normativa vigente. Secretaría de Economía, Departamento de Catastro. Bahía Blanca.

--- (2010). Ordenanza №15637 Plan Director del Periurbano Bahiense.

RíOS, L. y ROCCA M. J. (2014). Reconfiguración del territorio y política territorial: dispersión y baja densidad en las áreas de crecimiento reciente de la ciudad de Tandil, provincia de Buenos Aires. Territorios, 30, 109-126. 
THEODORE, N., PECK, J. y BRENNER, N. (2009). Urbanismo neoliberal: la ciudad y el imperio de los mercados. Temas Sociales: Ediciones SUR. Vol. 66.

ZINGER, A. y DEL POZO, O. (1990). Bahía Blanca: análisis de la aptitud del medio natural para la expansión urbana. Revista Universitaria de Geografía, Bahía Blanca: Universidad Nacional del Sur, Vol. IV, № 1 y $2,79-97$.

ZULAICA, L.; FERRARO, R. y VÁZQUEZ, P. (2012) Transformaciones territoriales en el periurbano de Mar del Plata. Geograficando, 8 (8), 169-187.

\section{Fuentes electrónicas}

INDEC: Unidades geoestadísticas https://geoservicios.indec.gov.ar/codgeo/index.php?pagina=definiciones (Consulta: $15 / 1 / 2018)$

MINISTERIO DE INFRAESTRUCTURA Y SERVICIOS PÚBLICOS, Registro Público Provincial de Villas y Asentamientos Precarios http://www.mosp.gba.gov.ar/subsecretarias/reg vilyasent.php (Consulta: 10/1/2018)

MINISTERIO DEL INTERIOR, OBRAS PÚBLICAS Y VIVIENDA. Planificación territorial. Bahía Blanca, expansión urbana. http://sig.planificacion.gob.ar/layers/buscar/?texto=bahia+blanca (Consulta: 4/9/2017)

MUNICIPALIDAD DE BAHÍA BLANCA, Registro Único de Postulantes http://gabierto.bahiablanca.gob.ar/datos-abiertos/agencia-urbana/tierras-y-viviendas/mas-barrios-sorteos-detierras-y-viviendas/registro-unico-de-postulantes/ (Consulta: 8/3/2016)

MUNICIPALIDAD DE BAHÍA BLANCA, Programa de Movilidad de suelo ocioso. http://gabierto.bahiablanca.gob.ar/mapa/movilidad-de-suelos/ (Consulta: 22/7/2014)

MUNICIPALIDAD DE BAHÍA BLANCA, Programa de Movilidad de suelo ocioso. Ordenanza Fiscal http://gabierto.bahiablanca.gob.ar/movilidad/doc/Ordenanza-Fiscal.pdf (Consulta: 22/7/2014) 